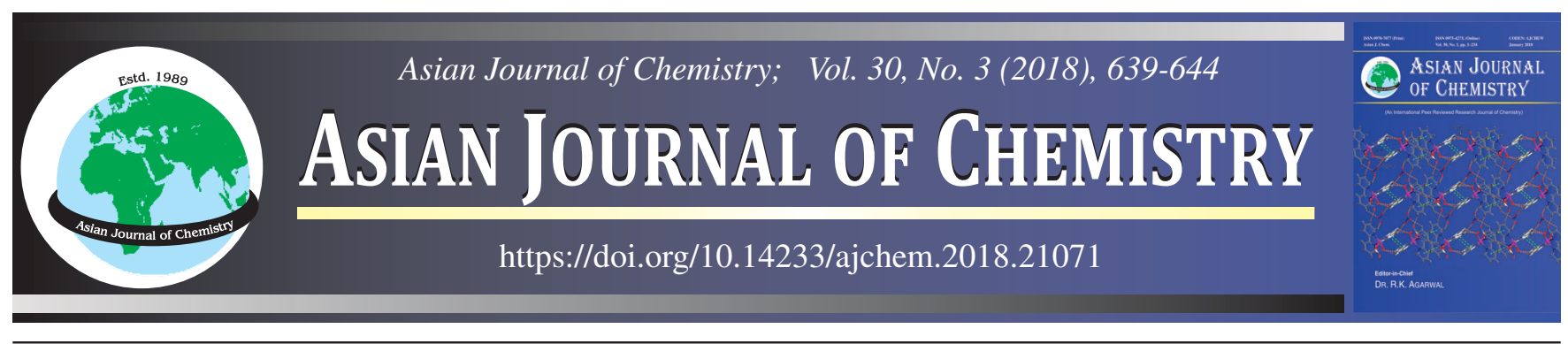

\title{
Solvent Free Facile Room Temperature Reduction of Aromatic Carbonyl and Nitro Compounds by Zn/Conc. HCI System-An Experimental and DFT Study
}

\section{S. RAJAMATHE ${ }^{1, *}$ and M. BHUVANESWARI ${ }^{2}$}

Department of Chemistry, Kanchi Mamunivar Centre for Post Graduate Studies, Puducherry-605 008, India

*Corresponding author: E-mail: rajamathi@gmail.com

Received: 29 September 2017;

Accepted: 28 November 2017;

Published online: 31 January 2018;

AJC-18758

This experimental and DFT studies involve a novel technique for the reduction of aromatic carbonyl/nitro compounds to the corresponding alcohols/amines, in high yield under laboratory conditions. The reducing species is the nascent hydrogen generated by the $\mathrm{Zn} / \mathrm{HCl}$ system. The novelty of this work is that the comparison of yield with and without solvent. The yield is increased by many folds in the solvent free method compared to the solvent method reported earlier. The technique followed is to make a 'slurry' of the substrate with zinc dust (zinc slurry) and to add (in small portion of the dry slurry) to the optimized amount of conc. $\mathrm{HCl}$, over a period of 3 to $4 \mathrm{~h}$ at room temperature. In this technique the substrate, adsorbed on zinc dust being very proximal to the site of generation nascent hydrogen, the reduction is very effective and the yield is high. The novelty is that zinc dust acts as catalyst (adsorbent role) and reactant (hydrogen generation role). The DFT study with B3LYP/6.311g ++ (d,p) basis set revealed that the stability of first formed free radical (energy factor) and the homo nuclear nature of carbonyl and nitro group (charge factor) decide the yield. The electrostatic potential calculated by DFT studies correlates well with Mullikan charges in deciding the charge factor. The free radical mechanism was confirmed by the formation of pinacol coupled product in one instance.

Keywords: Solvent free, Zinc slurry, Atomic hydrogen reduction, Carbonyl compounds, Nitro compounds, Mullikan charge.

ᄂ - - - - - - - - - - - - - - - - - - - - - - - - - - - - -

\section{INTRODUCTION}

The easiest functional group transformation which one can think of is the conversion of aromatic nitro group to amines and aromatic carbonyl group to alcohol/alkane and can be effected by reduction. Reduction is one of the frequently used reaction in organic synthesis and a vast variety of reducing agents have been introduced for this achievement [1,2]. The synthesis and biological evaluation of aromatic amines by derivative formation $[3,4]$ constitutes the most important study in chemistry. Likewise, the conversion of carbonyl compound to alcohol or alkane is important in pharmaceutical industries as the transformation changes the hydrophilicity of the compound.

A plethora of reducing agents is available for the reduction of aromatic carbonyl/nitro compounds claiming to be chemo/ regio/stereo-selective agents [5-11]. Inspite of the presence of mushroom of reducing agents for the reduction of aromatic carbonyl/nitro group, even though a few researchers [12-15] used zinc for reduction, including the recently reported reduction of graphene oxide to graphene by metal mediated direct electron transfer reduction [16-19] and metal mediated atomic hydrogen reduction $[20,21]$, the feasibility of using a commonly available non-toxic reagent which can act as the reducing agent at room temperature by the nascent hydrogen generated from $\mathrm{Zn} / \mathrm{HCl}$ system was only reported in earlier investigation [22] but the yield was poor.

The aims of the present investigation are to devise a method, which can enhance the yield of earlier investigation [22] and also confirm the principles derived from the DFT studies of the substrates used. This method is called 'solvent free slurry' (SFS) method. In this method, the substrates (carbonyl/nitro compounds) are not dissolved in any solvent (unlike earlier report [22] wherein the solvent used was $\mathrm{Et}_{2} \mathrm{O}$ ) but an intimate dry slurry of the substrate and zinc dust was prepared and used as substrate for the reduction in the presence of conc. $\mathrm{HCl}$. In this SFS method, zinc acts as a reactant and also a catalyst (adsorbent).

\section{EXPERIMENTAL}

All the reagents and substrates were purchased from commercial sources with A.R. quality and used without further purification. $\mathrm{SiO}_{2}$ was used in the form of silica gel 60 (70-230 mesh ASTM) and was purchased from Merck company. ${ }^{1} \mathrm{H}$ and ${ }^{13} \mathrm{C}$ NMR spectra were recorded on Bruker Avance DPX-400 $\mathrm{MHz}$ spectrometer. The products were characterized by comparison 
with authentic samples and their ${ }^{1} \mathrm{H}$ and ${ }^{13} \mathrm{C}$ NMR spectra. TLC was applied for the purity determination of substrates, products and the reaction monitoring was carried out using silica gel 60 $\mathrm{F}_{254}$ aluminum sheet.

General procedure for the reduction of aromatic carbonyl/ nitro compounds by solvent free slurry (SFS) method.

Preparation of slurry: As the starting materials for the investigation are known compounds, the experiments are performed in a higher scale for the ease of qualitative identification of the products. Zinc dust $(0.45 \mathrm{~mol})$ was added to $0.05 \mathrm{~mol}$ of aromatic carbonyl compound $/ 0.025 \mathrm{~mol}$ of aromatic nitro compound to make slurry. To reduce the viscosity, an excess Zn dust (about $10 \mathrm{~g}$ ) was added to make slurry for the aromatic carbonyl group/ nitro compound reduction. In case of solid subs-trate, a minimum amount of diethyl ether (about $15 \mathrm{~mL}$ ) was added and then treated with $\mathrm{Zn}$ dust for the slurry preparation. Slurry was warmed in water bath kept at $45^{\circ} \mathrm{C}$ for few minutes in order to evaporate diethyl ether.

Experimental procedure: In a typical experiment, 150 $\mathrm{mL}$ of conc. $\mathrm{HCl}$ of $1.8 \mathrm{~mol}$ was taken in $250 \mathrm{~mL}$ two-necked round bottom flask, which was kept in a water bath with stirring in order to maintain room temperature. To the stirred conc. $\mathrm{HCl}$ in a water bath, $0.45 \mathrm{~mol}$ of $\mathrm{Zn}$ dust in $0.05 \mathrm{~mol}$ of carbonyl substrate (slurry) $/ 0.025 \mathrm{~mol}$ of nitro substrate (slurry) was added very slowly through the spatula at a rate of $0.5 \mathrm{~g} / \mathrm{h}$, which was found to be the optimum rate of addition of product formation for maximum yield. As the generation of hydrogen from acid by zinc exothermic the water bath was kept in room temperature by monitoring the temperature by thermometer and maintaining the temperature by intermittently addition of ice cubes/ice water. The reaction was tested by several trial runs for optimum reaction time, which was monitored by TLC (8:2) hexane and ethyl acetate system as eluent. The reaction mixture was vigorously stirred at room temperature for the optimum reaction time of 4-5 h.

After the completion of reaction, the mixture was filtered using a Whatmann filter paper No. 42 and extracted with diethyl ether. To the aqueous layer, $100 \mathrm{~mL}$ of $20 \%$ aqueous $\mathrm{NaCl}$ was added (salting out effect) and extracted with diethyl ether again. On repeating the procedure 3-4 times, the multiple extracted fractions were combined and dried over anhydrous $\mathrm{Na}_{2} \mathrm{SO}_{4}$ and then the solvent was evaporated under reduced pressure (rotor evaporator) to obtain the crude product. The mixture NMR of the crude was obtained to determine the product to reactant ratio, character-ization and to find the conversion percentage.

The general scheme for the reduction by $\mathrm{Zn} / \mathrm{conc}$. HCl using solvent free slurry (SFS) method of aromatic carbonyl and nitro groups is given in Scheme I and II, respectively.

After adopting the experimental procedure described in the experimental section, ${ }^{1} \mathrm{H}$ NMR and ${ }^{13} \mathrm{C}$ NMR of crude products are obtained. The ${ }^{1} \mathrm{H}$ NMR was used for fixing the ratios of the products formed and the nature of the products formed. The principle for fixing the yield ratio is that when a carbonyl group is converted to alcohol/alkane, or when a nitro group is converted to hydroxylamine or amine, the aromatic protons of products appear slightly up field in comparison to the aromatic protons of the substrate (starting material). As most of the products formed are known compounds the products peaks are identified by comparing them with the authentic spectra available in NMR data

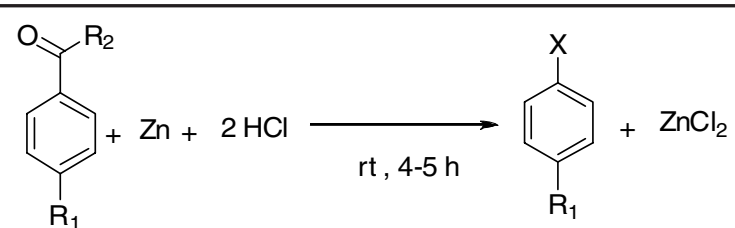

1. $\mathrm{R}^{1}=\mathrm{H} ; \mathrm{R}^{2}=\mathrm{H}$

6. $\mathrm{R}^{1}=\mathrm{H} ; \mathrm{X}=\mathrm{CH}(\mathrm{OH}) \mathrm{CH}(\mathrm{OH}) \mathrm{C}_{6} \mathrm{H}_{5}$

2. $\mathrm{R}^{1}=\mathrm{OCH}_{3} ; \mathrm{R}^{2}=\mathrm{H}$

7. $\mathrm{R}^{1}=\mathrm{OCH}_{3} ; \mathrm{X}=\mathrm{CH}_{3}$

3. $\mathrm{R}^{1}=\mathrm{H} ; \mathrm{R}^{2}=\mathrm{CH}_{3}$

8. $\mathrm{R}^{1}=\mathrm{H} ; \mathrm{X}=\mathrm{C}\left(\mathrm{CH}_{3}\right)\left(\mathrm{C}_{6} \mathrm{H}_{5}\right) \mathrm{COCH}_{3}$

4. $\mathrm{R}^{1}=\mathrm{H} ; \mathrm{R}^{2}=\mathrm{C}_{6} \mathrm{H}_{5}$

9. $\mathrm{R}_{1}=\mathrm{H} ; \mathrm{X}=\mathrm{C}(\mathrm{OH})\left(\mathrm{C}_{6} \mathrm{H}_{5}\right) \mathrm{C}(\mathrm{OH})\left(\mathrm{C}_{6} \mathrm{H}_{5}\right)_{2}$

5. $\mathrm{R}^{1}=\mathrm{H} ; \mathrm{R}^{2}=\mathrm{COC}_{6} \mathrm{H}_{5}$

10. $\mathrm{R}_{1}=\mathrm{H} ; \mathrm{X}=\mathrm{CH}_{2} \mathrm{CH}_{2} \mathrm{C}_{6} \mathrm{H}_{5}$

11. $\mathrm{R}_{1}=\mathrm{H} ; \mathrm{X}=\mathrm{COCH}_{2} \mathrm{C}_{6} \mathrm{H}_{5}$

Scheme-I: Reduction of aromatic carbonyl compounds (1-5)

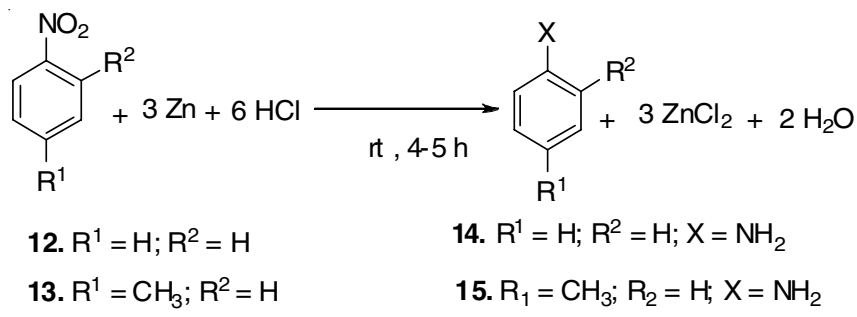

Scheme-II: Reduction of aromatic nitro compounds (12-13)

base [23]. The ratio of aromatic peak area of the substrate and that of products is a measure of yield and percentage of conversion. The absence of the substrate's characteristic peak in the NMR spectra of the products is an indication of improvement in the yield and that will serve present objective of enhancing the yield under the experimental conditions.

\section{Spectral data}

1,2-Diphenylethane-1,2-diol (6): ${ }^{1} \mathrm{H}$ NMR: $(400 \mathrm{MHz}$, $\left.\mathrm{CDCl}_{3}\right) \delta 4.739(\mathrm{~s}, 1 \mathrm{H}), 5.36$ (s, $1 \mathrm{H}$, hydroxyl protons), 6.937.11 (m, $10 \mathrm{H}$, aromatic protons) ppm; ${ }^{13} \mathrm{C}$ NMR: $(100 \mathrm{MHz}$, $\left.\mathrm{CDCl}_{3}\right) \delta 77.89,126.80,127.92,128.07,139.38 \mathrm{ppm}$.

1-Methoxy-4-methylbenzene (7): ${ }^{1} \mathrm{H}$ NMR: $(400 \mathrm{MHz}$, $\left.\mathrm{CDCl}_{3}\right) \delta 2.33(\mathrm{~s}, 3 \mathrm{H}), 3.82(\mathrm{~s}, 3 \mathrm{H}), 6.84-6.87$ and 7.12-7.14 (m, 5H, aromatic protons); ${ }^{13} \mathrm{C} \mathrm{NMR:}\left(100 \mathrm{MHz}, \mathrm{CDCl}_{3}\right) 20.55$, 55.31, 113.70, 129.91, 129.99, $157.55 \mathrm{ppm}$.

3,3-Diphenylbutan-2-one (8): ${ }^{1} \mathrm{H}$ NMR: $(400 \mathrm{MHz}$, $\left.\mathrm{CDCl}_{3}\right) \delta 1.76(\mathrm{~s}, 3 \mathrm{H}), 1.99(\mathrm{~s}, 3 \mathrm{H}), 7.08-7.24(\mathrm{~m}, 10 \mathrm{H}$ aromatic protons); ${ }^{13} \mathrm{C}$ NMR: (100 MHz, $\left.\mathrm{CDCl}_{3}\right) \delta 26.49,27.66,62.37$, 126.97, 128.36, 128.41,143.64, $209.19 \mathrm{ppm}$.

1,1,2,2-Tetraphenylethane-1,2-diol (9): ${ }^{1} \mathrm{H}$ NMR: (400 $\left.\mathrm{MHz}, \mathrm{CDCl}_{3}\right) \delta 2.96$ (s, 1H, hydroxyl protons), 7.08-7.23 (m, $20 \mathrm{H}$, aromatic protons) ppm; ${ }^{13} \mathrm{C}$ NMR: $\left(100 \mathrm{MHz}, \mathrm{CCl}_{4}-\right.$ $\left.\mathrm{CDCl}_{3}\right) \delta 83.15,127.08,127.43,128.74,144.29 \mathrm{ppm}$.

Diphenylethane (10): ${ }^{1} \mathrm{H}$ NMR (400 MHz, $\left.\mathrm{CDCl}_{3}\right) \delta 3.07$ (s, $2 \mathrm{H}), 7.06-7.49$ (m, 10H, aromatic protons) $\mathrm{ppm} ;{ }^{13} \mathrm{C} \mathrm{NMR}$ : $\left(100 \mathrm{MHz}, \mathrm{CDCl}_{3}\right) \delta 38.01,125.99,128.70,130.97,141.83$ ppm.

1,2-Diphenylethanone (11): ${ }^{1} \mathrm{H} \mathrm{NMR}:\left(400 \mathrm{MHz}, \mathrm{CDCl}_{3}\right)$ $\delta 4.40(\mathrm{~s}, 2 \mathrm{H}), 7.34-7.49$ and $8.10-8.20(\mathrm{~m}, 10 \mathrm{H}$, aromatic protons) ppm; $\left.{ }^{13} \mathrm{C} \mathrm{NMR:} \mathrm{(100} \mathrm{MHz,} \mathrm{CDCl}_{3}\right) \delta 45.40,126.80$, $128.53,129.56,133.29,136.76,197.50 \mathrm{ppm}$.

Aniline (14): ${ }^{1} \mathrm{H}$ NMR $\left(400 \mathrm{MHz}, \mathrm{CDCl}_{3}\right) \delta 3.65\left(\mathrm{NH}_{2}\right.$ broad signal), 6.69-6.71 (d, $1 \mathrm{H}$, aromatic proton) ppm, 6.67$6.81(\mathrm{~m}, 2 \mathrm{H}$, aromatic protons) 7.16-7.20 (m, $2 \mathrm{H}$, aromatic 
protons) ppm; ${ }^{13} \mathrm{C}$ NMR: $\left(100 \mathrm{MHz}, \mathrm{CDCl}_{3}\right) \delta 115.11,118.50$, 129.30, $146.47 \mathrm{ppm}$.

p-Toluidine (15): ${ }^{1} \mathrm{H}$ NMR: (400 MHz, $\left.\mathrm{CDCl}_{3}\right) \delta 2.29$ (s, $3 \mathrm{H}), 3.40\left(\mathrm{NH}_{2}\right.$ protons $), 6.63-6.6 \mathrm{~m}$ ( $\mathrm{m}, 3 \mathrm{H}$, aromatic protons), 7.00-7.02 (m, 2H, aromatic protons) ppm; ${ }^{13} \mathrm{CNMR}:(100 \mathrm{MHz}$, $\left.\mathrm{CDCl}_{3}\right) \delta 20.47,115.32,127.77,129.78,143.88 \mathrm{ppm}$.

Theoretical studies: The yield percentage of the reduced products can only be reasoned out by theoretical studies, so as reported in earlier study [22], DFT calculations were performed in order to calculate the energy difference between the energy of optimized geometry of the substrates and that of first formed free radicals. The DFT calculations were performed at B3LYB/ $6.311 \mathrm{~g}++(\mathrm{d}, \mathrm{p})$ level of theory by using the quantum mechanical calculation Software (Gaussian 03) program. From the geometry optimized substrate Mullikan charges were also obtained. In addition to those calculations, now we have performed electrostatic potential (ESP) calculation of the geometry optimized substrates to study the correlation between electrostatic potential and Mullikan charges (calculated earlier [22]), in deciding the homonuclear nature of bond $(\pi)$ present in the carbonyl and nitro compounds.

The electronegativity difference of carbonyl and nitro group in as substrate can be calculated from the residual partial charges on the atoms of geometry optimized substrate molecules and is called Mullikan charges. The Mullikan charges for carbon and oxygen atoms of the carbonyl group and nitrogen, and oxygen of nitro group, are obtained from the geometry optimized substrates. The electronegativity difference or homonuclear nature is denoted as charge factor. It is arrived by adding the magnitudes of 'unlike' Mullikan charges and by subtracting the magnitude of 'like' Mullikan charges on $\mathrm{C}$ and $\mathrm{O}$ atoms in case of carbonyl group and on $\mathrm{N}$ and $\mathrm{O}$ atoms in the case of nitro group of the substrates. The charge factor is an approximate measure of the electronegativity difference of the atoms involved, lesser the charge factor, more is the homonuclear nature of $(\pi)$ bond present between the atoms $(\mathrm{C} / \mathrm{O}$ or $\mathrm{N} / \mathrm{O})$ and hence more likely is the homolytic fission of $(\pi)$ bond in second step of the suggested mechanisms [22], resulting in more yield.

\section{RESULTS AND DISCUSSION}

The results of present investigation are given in Table-1. Apart from the usual reduction products, an unexpected pinacol coupled and rearranged products 6,8 and 9 were also obtained. The formation of pinacol coupled products $\mathbf{6 , 9}$ is in accordance with report of Ranu et al. [23]. The formation of pinacol rearranged product $\mathbf{8}$ is in accordance with the report of Salama et al. [24]. The formation of bibenzyl $\mathbf{1 0}$ is in accordance with report of Mahajan et al. [25]. All the reduced products are obtained at room temperature, in solvent free condition (SFSM) within 4-5 h. The yield percentages of the reduced products are very high in solvent free slurry (SFS) method, in comparison with solvent method. The conversion rate for all the reduction reactions are $100 \%$, as we found the absence of characteristic peaks of the starting materials in ${ }^{1} \mathrm{H}$ and ${ }^{13} \mathrm{C}$ NMR spectra of the crude. For ease of comparison, the yields of two methods are presented in Table-2.

The mechanism of zinc/conc. $\mathrm{HCl}$ reduction has been obscure right from the era of Clemmenson [26-28]. There are
TABLE-1

DETAILS OF THE REDUCED PRODUCTS OF THE AROMATIC CARBONYL (6-11) AND NITRO COMPOUNDS (14-15) BY SFSM

\begin{tabular}{ccccc}
\hline Entry & $\mathrm{R}^{1}$ & $\mathrm{R}^{2}$ & $\begin{array}{c}\text { Compound } \\
\text { number }\end{array}$ & Yield*(\%) \\
\hline 1 & $\mathrm{H}$ & $\mathrm{H}$ & $\mathbf{6}$ & 80 \\
2 & $\mathrm{OCH}_{3}$ & $\mathrm{H}$ & $\mathbf{7}$ & 50 \\
3 & $\mathrm{H}$ & $\mathrm{CH}_{3}$ & $\mathbf{8}$ & 60 \\
4 & $\mathrm{H}$ & $\mathrm{C}_{6} \mathrm{H}_{5}$ & $\mathbf{9}$ & 90 \\
5 & $\mathrm{H}$ & $\mathrm{COC}_{6} \mathrm{H}_{5}$ & $\mathbf{1 0}$ & $70^{* *}$ \\
6 & $\mathrm{H}$ & $\mathrm{H}$ & $\mathbf{1 4}$ & 75 \\
7 & $\mathrm{CH}_{3}$ & $\mathrm{H}$ & $\mathbf{1 5}$ & 60 \\
\hline
\end{tabular}

*isolated crude with negligible minor products; $* *$ with minor amount of compound 11

TABLE-2

COMPARISON OF THE YIELDS OF REDUCED PRODUCTS OF THE AROMATIC CARBONYL (6-10) AND NITRO COMPOUNDS (14-15) BY SFSM AND SM

\begin{tabular}{ccccc}
\hline Entry & $\mathrm{R}^{1}$ & $\mathrm{R}^{2}$ & $\begin{array}{c}\text { Yield (\%) } \\
\text { (solvent } \\
\text { method)* }\end{array}$ & $\begin{array}{c}\text { Yield (\%) } \\
\text { (solvent free } \\
\text { slurry method)** }\end{array}$ \\
\hline 1 & $\mathrm{H}$ & $\mathrm{H}$ & 42 & 80 \\
2 & $\mathrm{OCH}_{3}$ & $\mathrm{H}$ & 4 & 50 \\
3 & $\mathrm{H}$ & $\mathrm{CH}_{3}$ & 13 & 60 \\
4 & $\mathrm{H}$ & $\mathrm{C}_{6} \mathrm{H}_{5}$ & 42 & 90 \\
5 & $\mathrm{H}$ & $\mathrm{COC}_{6} \mathrm{H}_{5}$ & 25 & 70 \\
6 & $\mathrm{H}$ & $\mathrm{H}$ & 25 & 75 \\
7 & $\mathrm{CH}_{3}$ & $\mathrm{H}$ & 5 & 60 \\
\hline
\end{tabular}

*culled from ${ }^{1} \mathrm{H}$ mixture NMR spectra containing starting material; **isolated crude with negligible minor products.

two schools thought, One group [29] emphasizes the non-existence of species called 'nascent hydrogen' (atomic hydrogen), and the reduction involves only direct transfer electron by the metal (zinc) to substrate, not to $\mathrm{H}^{+}$ions [16-19]. There are two mechanistic pathways suggested by this group [28,30].

The first mechanism (zinc-carbenoid) [26] suggested the involvement of the transfer of an electron from zinc metal to carbonyl group of ketone, leading to a radical species which is presumed to react further to yield zinc-carbenoid species. Upon subsequent addition of protons, methylene product is formed. Zinc-carbenoid mechanism does not involve alcohol intermediate. The second mechanism (carbanion) [24] as suggested involves ionic mecha-nism, in which after the protonation of oxygen of the carbonyl group, metal transfers electrons to the carbocation of ketone, formed after the protonation of oxygen of carbonyl group. The electron transfer results in the formation of metal-carbon bond leading to the formation of $\alpha$-hydroxy alkyl zinc chloride intermediate. The intermediate leads to carbanion intermediate by the elimination of $\mathrm{H}_{2} \mathrm{O}$ and $\mathrm{ZnCl}_{2}$. The carbanion again eliminates $\mathrm{ZnCl}_{2}$ and forms the product on protonation.

We firmly believed that the above mentioned mechanisms do not operate in earlier studies [22] and present investigations due to the following reasons: (a) Some of the products obtained earlier/present studies are pinocol-coupled products (compound $\mathbf{6 , 9}$ ), rearranged pinacol-coupled product (compound $\mathbf{8}$ ) and alcoholic product (compound 16). The formation of these products cannot be explained by zinc-carbenoid/carbanion mechanisms. (b) The experimental conditions in present investigation is highly acidic. Under these conditions, zinc metal cannot transfer electron 
to carbonyl carbon or oxygen, but it can only transfer electron to $\mathrm{H}^{+}$ions. Based on its high redox potential, $\mathrm{H}^{+}$ions receive electrons from metal to form nascent hydrogen (atomic hydrogen), which reduces carbonyl/nitro group. The reduction by atomic hydrogen has also been recently reported in the study reduction of graphene oxide to graphene [20,21]. (c) The increase in the yield from solvent method to solvent free slurry (SFS) method is an evidence for the reduction by atomic hydrogen. The enhanced yields are due to the decrease in the distance ' $b$ ' between the substrate and nascent hydrogen in solvent method to ' $a$ ' in solvent free slurry method (Figs. 1 and 2). (d) As shown Figs 1 and 2, there are two competitive reactions in the system, one is reduction of the substrate by atomic hydrogen (path A) and other is recombination of atomic hydrogen atoms to form hydrogen molecules (path B), of which the reduction is favoured in solvent free slurry method (SFSM) due to the proximity (distance 'a') of the substrate and atomic hydrogen in SFSM. The adsorption of substrate on zinc metal (during slurry preparation) is physical adsorption only and is not chemical adsorption, as zinc does not react with substrate but react with $\mathrm{H}^{+}$ions to produce the atomic hydrogen. This is evident from the fact that more of pinacol coupled products are formed in solvent free slurry method (SFSM), as the carbon free radicals formed in the process of atomic hydrogen reduction are proximal due to the physical

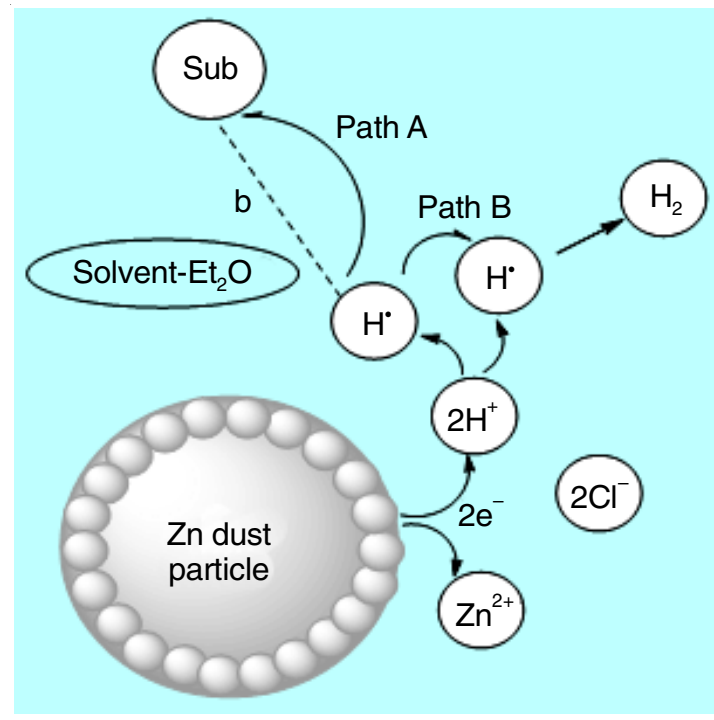

Fig. 1. Solvent method (SM)

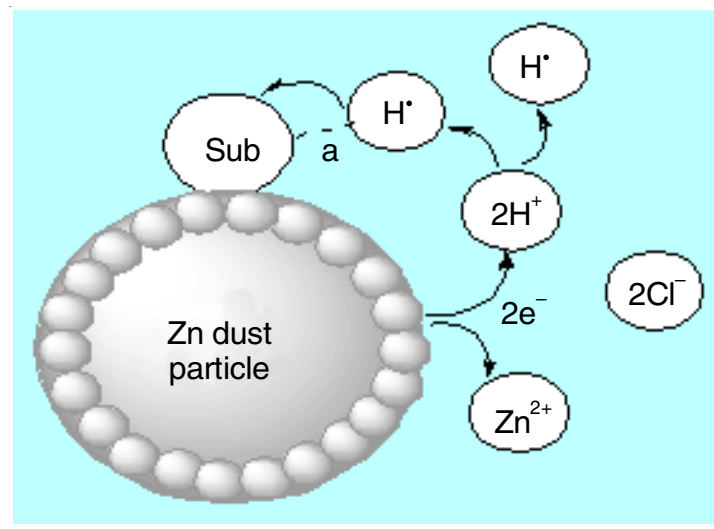

Fig. 2. Solvent free slurry method (SFSM) adsorption and they easily undergo coupling and rearrangement. Present finding is a path breaking and contrary to the general belief that there is no such thing called 'nascent hydrogen'.

The above mentioned facts ruled out the metal mediated direct electron transfer mechanism and hence present investigations should follow metal mediated atomic hydrogen reduction (free radical) mechanism suggested in earlier investigation [22] which was also based on the studies of Martin et al. [31]. According to the suggested mechanisms, the success of carbonyl/nitro group reduction depends on three factors: (i) Homonuclear nature of carbonyl group and nitro group. It is decided by the electronegatively difference of carbonyl carbon and oxygen atoms present in the carbonyl compound and in the case of nitro compound, it depends on the electronegativitiy difference of nitrogen and oxygen atoms of the given nitro compound. (ii) Stability of the free radical intermediates formed in the second step of both mechanisms, and (iii) Distance between the generated nascent hydrogen and substrate molecule.

The third factor is taken care by preparing a intimate slurry of the substrate and zinc in solvent free slurry (SFS) method. Present aim was to quantify the first two factors and correlate them with the experimental yields and a positive correlation serves as a support for the suggested mechanism. With this aim, the DFT calculations were performed at B3LYB/6.311g $++(\mathrm{d}, \mathrm{p})$ level of theory by using the quantum mechanical calculation software (Gaussian 03) program in earlier study [22] to find 'energy factor' and 'charge factor'. Now in the present study, electrostatic potential (ESP) calculation of geometry optimized substrates were performed to study the correlation between electrostatic potential and Mullikan charges (calculated earlier [22]), in deciding the homo nuclear nature of $\pi$-bond present in carbonyl and nitro compounds.

In present study, we found that charge factor can also be correlated to calculated electrostatic potential of substrate. More, the negative electrostatic potential on oxygen atom of carbonyl or nitro group, more is the charge factor for substrate and less is the yield as illustrated in Figs. 3 and 4. For substrate 4, the electrostatic potential correlates well with the prediction made from Mullikan charges for all substrates but for substrate 5 it is not, which is due the fact that the positive potential on carbonyl carbon is more (indicated by intense blue color in electrostatic potential structure).

The energy difference between the substrate and first formed free radical is called 'energy factor' and its value decides the further course of action in both mechanisms. So, from the DFT calcul-
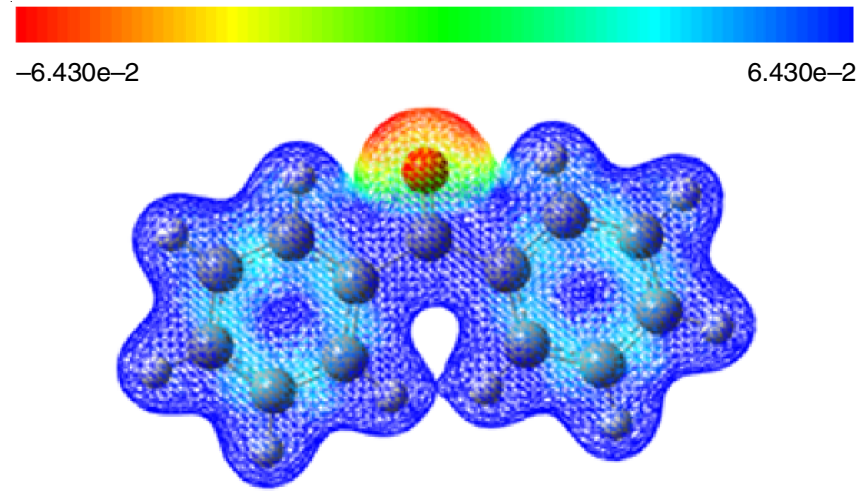

Fig. 3. Electrostatic potential (ESP) structure of benzophenone (4) 


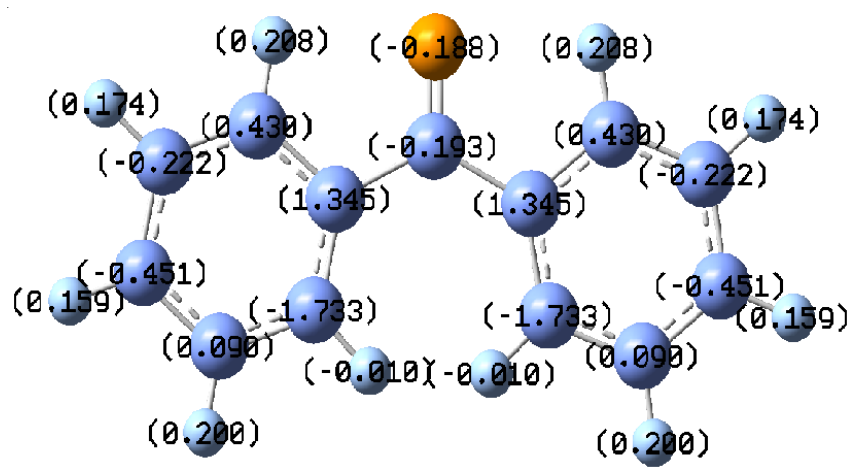

Fig. 4. Mullikan charges for geometry optimized structure of benzophenone (4)

ations $\mathrm{E}_{\text {substrate }}-\mathrm{E}_{\text {Free radical }}$ were obtained to quantify the energy factor. Higher value the energy factor, more stable is the free radical because energy factor indicates how much lower is the energy of free radical when compared to the substrate from which it formed. The results obtained showed the following trend in charge factor and energy factor for carbonyl and nitro compounds.

Charge factor: Smaller the charge factor, more is the probability of free radical production by homolytic fission (yield).

(i) Carbonyl compounds: 0.005 (benzophenone) $<0.018$ (acetophenone) < 0.094 (benzaldehyde) $<0.191$ (4-methoxybenzaldehyde) $<0.302$ (benzil).

(ii) Nitro compounds: 0.118 (nitrobenzene) $<0.138$ (2-nitrobenzaldehyde)

Energy factor: Higher energy factor more is the stability of free radical and yield.

(i) Carbonyl compounds: 1532.338 (benzil) > 1527.651 (benzophenone) > 1487.420 (benzaldehyde) > 1480.798 (acetophenone) $>1478.341$ ( 4-methoxybenzaldehyde).

(ii) Nitro compounds: 1537.578 ( 4-nitrobenzene) $>1534.744$ 4-nitrotoulene.

The results are presented in Table-3 along with yields obtained earlier [32] and present study. For positive correlation $1 /$ charge factor is also presented in Table-3. It is heartening to observe that the yield prediction from the values of charge factor and energy factor (which are based on the suggested mechanisms) agrees very well with the experimental yield and thereby supported the metal mediated atomic hydrogen reduction (free radical) mechanism. It is also observed that in case of substrate $\mathbf{5}$, the charge factor takes an upper hand over the energy factor. So from the results obtained, one can conclude both factors are important for high yield, with the charge factor having an edge over energy factor.

\section{Conclusions}

The investigations of solvent free facile room temperature reduction of aromatic carbonyl and nitro group by $\mathrm{Zn} /$ conc. $\mathrm{HCl}$ highlighted the following factors:

- In complement to earlier investigation [21] in same theme, the present study also confirms that reduction of aromatic carbonyl and nitro group by $\mathrm{Zn} / \mathrm{conc}$. $\mathrm{HCl}$, is only by generated hydrogen free radical (nascent hydrogen) and not by metal mediated direct electron transfer. It also confirms that the yield of product depends both the stability of free radical generated (in second step of suggested mechanisms), denoted as energy factor and the charge factor, which makes $\pi$-bond of both nitro and carbonyl group amenable for homolytic fission, which is a precondition for the free radical reactions.

- It is also found that apart from Mullikan charges, the electrostatic potential calculated by DFT method, can also be useful in quantifying the charge factor.

- The yield of reductions products are high, due to the proximity of the substrate and liberated nascent hydrogen under the experimental conditions (SFS method).

- Due to the adsorption of substrate on zinc surface which acts as a catalyst and reactant, the radical intermediates formed are also proximate and undergo coupling to yield unexpected coupled and rearranged products.

- The reaction is facile as it involves cheap chemicals, less reaction time and more yields and hence, this method can be included in the undergraduate curriculum as a preferred alternate method for the synthesis of the reported reduced product (aniline, toluidine, etc.).

- In the adopted experimental method (SFS method), the most elusive nascent hydrogen was tamed and used effectively for the efficient reduction in a situation where competitive reaction is possible. So in future investigations, the reduction efficiency of this method for reducing aromatic alkenes, esters and amides would be investigated.

\section{ACKNOWLEDGEMENTS}

The authors are thankful to Prof. Dr. H. Surya Prakash Rao, Department of Chemistry, School of Physical, Chemical \& Applied Sciences, Pondicherry University, Puducherry, India and his research scholars for their encouragement, support

TABLE-3

ENERGY DIFFERENCE OF THE GEOMETRY OPTIMIZED SUBSTRATES (1-5) AND (12-13) AND THEIR FREE RADICALS (B3LYB/6.311g ++ (d,p) ) WITH ESP/CHARGE/ENERGY FACTORS AND YIELD OF SM/SFSM

\begin{tabular}{|c|c|c|c|c|c|c|c|}
\hline S. No. & $\begin{array}{l}\text { Compound } \\
\text { name }\end{array}$ & $\begin{array}{c}\text { Energy difference } \\
(\mathrm{kJ} / \mathrm{mol}) \text { (Energy } \\
\text { factor) }\end{array}$ & $\begin{array}{c}\text { ESP of oxygen } \\
\text { atom }(\mathrm{V})\end{array}$ & $\begin{array}{c}\text { Charge } \\
\text { difference } \\
\text { (Charge factor) }\end{array}$ & $\begin{array}{l}\text { 1/Charge } \\
\text { difference }\end{array}$ & $\begin{array}{l}\text { Yield }(\%) \\
(\mathrm{SM})\end{array}$ & $\begin{array}{c}\text { Yield }(\%) \\
(\text { SFSM) }\end{array}$ \\
\hline 1 & Benzaldehyde & 1487 & $-7.526 \times 10^{-2} *$ & 0.094 & 10.6 & 42 & 80 \\
\hline 2 & Anisole & 1478 & $-8.242 \times 10^{-2}$ & 0.191 & 5.2 & 4 & 50 \\
\hline 3 & Acetophenone & 1481 & $-7.848 \times 10^{-2}$ & 0.018 & 55.6 & 13 & 60 \\
\hline 4 & Benzophenone & 1528 & $-6.430 \times 10^{-2}$ & 0.005 & 200.0 & 42 & 90 \\
\hline 5 & Benzil & 1532 & $-5.118 \times 10^{-2} *$ & 0.302 & 3.3 & 25 & 70 \\
\hline 6 & Nitrobenzene & 1538 & $-6.223 \times 10^{-2}$ & 0.118 & 8.5 & 25 & 75 \\
\hline 7 & 4-Nitrotoluene & 1535 & $-6.667 \times 10^{-2}$ & 0.140 & 7.1 & 5 & 60 \\
\hline
\end{tabular}

*The potential on carbonyl carbon is more positive. 
rendered in recording the NMR spectra. Thanks are also due to the Director, Kanchi Mamunivar Centre for Post Graduate Studies, Puducherry and The Government of Puducherry, for providing the infrastructure in the Department of Chemistry of the College to carry out this research work.

\section{REFERENCES}

1. S.D. Burke and R.L. Danheiser, Handbook of Reagents for Organic Synthesis, Oxidizing and Reducing Agents, Wiley-VCH: New York, (1999).

2. F. Yuste, M. Saldana and F. Walls, Tetrahedron Lett., 23, 147 (1982); https://doi.org/10.1016/S0040-4039(00)86770-2.

3. R.E. Lyle and J.L. LaMattina, Synthesis, 726 (1974); https://doi.org/10.1055/s-1974-23423.

4. R.S. Dhillon, Hydroboration and Organic Synthesis, Springer: Germany (2007).

5. S.H. Lee, M.H. Nam, M.Y. Cho, B.W. Yoo, H.J. Rhee and C.M. Yoon, Synth. Commun., 36, 2469 (2006); https://doi.org/10.1080/00397910600781224.

6. A.Z. Halimjani and M.R. Saidi, Synth. Commun., 35, 2271 (2005); https://doi.org/10.1080/00397910500186177.

7. B. Zeynizadeh and S. Yahyaei, Bull. Korean Chem. Soc., 24, 1664 (2003); https://doi.org/10.5012/bkcs.2003.24.11.1664.

8. B. Uysal and B.S. Buyuktas, ARKIVOC, 134 (2007); https://doi.org/10.3998/ark.5550190.0008.e14.

9. S. Chandrasekhar, S.J. Prakash and C.L. Rao, J. Org. Chem., 71, 2196 (2006); https://doi.org/10.1021/jo052604x.

10. D. Lee, D. Kim and J. Yun, Angew. Chem. Int. Ed., 45, 2785 (2006); https://doi.org/10.1002/anie.200600184.

11. B.C. Ranu, A. Majee and A.R. Das, Tetrahedron Lett., 36, 4885 (1995); https://doi.org/10.1016/00404-0399(50)0877F-

12. H.M. Meshram, G.S. Reddy, M.M. Reddy and J.S. Yadav, Tetrahedron Lett., 39, 4103 (1998); https://doi.org/10.1016/S0040-4039(98)00666-2.

13. H.M. Meshram, G.S. Reddy, M.M. Reddy and J.S. Yadav, Synth. Commun., 28, 2203 (1999); https://doi.org/10.1080/00397919808007034.

14. J.S. Yadav, G.S. Reddy, M.M. Reddy and H.M. Meshram, Tetrahedron Lett., 39, 3259 (1998); https://doi.org/10.1016/S0040-4039(98)00464-X.
15. Z. Fan, K. Wang, T. Wei, J. Yan, L. Song and B. Shao, Carbon, 48, 1686 (2010); https://doi.org/10.1016/j.carbon.2009.12.063.

16. Z. Fan, W. Kai, J. Yan, T. Wei, L.-J. Zhi, J. Feng, Y. Ren, L.-P. Song and F. Wei, ACS Nano, 5, 191 (2011); https://doi.org/10.1021/nn102339t

17. X. Mei and J. Ouyang, Carbon, 49, 5389 (2011); https://doi.org/10.1016/j.carbon.2011.08.019.

18. R.S. Dey, S. Hajra, R.K. Sahu, C.R. Raj and M.K. Panigrahi, Chem. Commun., 48, 1787 (2012): https://doi.org/10.1039/C2CC16031E.

19. V.H. Pham, H.D. Pham, T.T. Dang, S.H. Hur, E.J. Kim, B.S. Kong, S. Kim and J.S. Chung, J. Mater. Chem., 22, 10530 (2012); https://doi.org/10.1039/c2jm30562c.

20. B.K. Barman and K.K. Nanda, Chem. Commun., 49, 8949 (2013); https://doi.org/10.1039/c3cc44813d.

21. S. Rajamathe and G. Selvaraj, Asian J. Chem., 29, 1761 (2017); https://doi.org/10.14233/ajchem.2017.20623.

22. Spectral Database for Organic Compounds (SDBS), National Institute of Advanced Industrial Science and Technology (AIST), Japan.

23. B.C. Ranu, J. Dutta and U. Jana, J. Indian Inst. Sci., 81, 139 (2001).

24. T.A. Salama, S.S. Elmorsy and A.-G.M. Khalil, Tetrahedron Lett., 48, 4395 (2007); https://doi.org/10.1016/j.tetlet.2007.04.092.

25. S.S. Mahajan and V.A. Kamath, Indian J. Chem., 44B, 1713 (2005)

26. E. Clemmensen, Ber. Dtsch. Chem. Ges., 46, 1837 (1913); https://doi.org/10.1002/cber.19130460292.

27. E.L. Martin, Org. React., 1, 155 (1942); https://doi.org/10.1002/0471264180.or001.07.

28. E. Vedejs, Org. React., 22, 401 (1975); https://doi.org/10.1002/0471264180.or022.03.

29. J. Burdon and R.C. Price, J. Chem. Soc. Chem. Commun., 893 (1986); https://doi.org/10.1039/c39860000893.

30. F. Laborda, E. Bolea, M.T. Baranguan and J.R. Castillo, Spectrochim. Acta B At. Spectrosc., 57, 797 (2002); https://doi.org/10.1016/S0584-8547(02)00010-1.

31. J.N. Pitts Jr., R.L. Letsinger, R.P. Taylor, J.M. Patterson, G. Recktenwald and R.B. Martin, J. Am. Chem. Soc., 81, 1068 (1959); https://doi.org/10.1021/ja01514a014.

32. A. Demeter, B. László and T. Bérces, Ber. Bunsenges. Phys. Chem, 92 , 1478 (1988); https://doi.org/10.1002/bbpc.198800355. 